Araştırma Makalesi / Research Article

Geliş tarihi / Received:10.01.2021

Kabul tarihi / Accepted: 29.04.2021

Atıf İçin: Aybeke M, 2021. Bazı Ophrys Taksonlarında Labellum Mikromorfolojisi. Iğdır Üniversitesi Fen Bilimleri Enstitüsü Dergisi, 11(3): 1742-1750.

To Cite: Aybeke M, 2021. Labellum Micromorphology in Some Ophrys Taxa. Journal of the Institute of Science and Technology, 11(3): 1742-1750.

\title{
Bazı Ophrys Taksonlarında Labellum Mikromorfolojisi
}

\section{Mehmet AYBEKE}

ÖZET: Çalışmada 10 değişik Ophrys taksonuna ait örneklerde labellum mikromorfolojisi Taramalı Elektron mikroskobu (SEM) yöntemi ile incelenmiş ve sonuçlar karşılaştırmalı tablolar halinde sunulmuştur. Örnekler, araziden toplandığı sırada \%70 alkole alınmış, bir kısmı da herbaryum kurallarına göre kurutularak teşhisleri yapılmıştır. Alkolden çıkarılan labellum örnekleri, bisturi ve iğnelerle stereomikroskop altında dissekte edilerek doğrudan _üzeri çift taraflı yapışkan bantlar bulunan_ve SEM cihazına ait çelik aparatlara yerleştirilmiştir. Bir gece kadar bekletilerek alkolü tamamıyla uçurulan bu örnekler, doğrudan Taramalı Elektron Mikroskobu (SEM) ile incelenmiş ve labellum mikrofotoğrafları çekilmiştir. Bulgularımıza göre spekulum yapılarının birbirinden çok farklı olduğu, bazal, medyan, lateral bölgelerde tüy / papilla şekli ve dağılımının türden türe farklılık gösterdiği tespit edilmiştir. Ayrıca apeks bölgesinin O. fusca, O. lutea var. minor, O. speculum, O. mammosa, O. pseudomammosa, $O$. heldreichii, $O$. umbilicata, $O$. holoserica türlerinde de farklılık gösterdiği tespit edilmiştir. Özetle; 1. derecede labellum spekulum ve apeks yapısının, 2. derecede de bazal, medyan ve lateral bölge yüzey karakterlerinin türler arasında çok farklılık gösterdiği sonucuna varılmıştır.

Anahtar Kelimeler: Orchidaceae, Ophrys, çiçek, labellum, morfoloji, petal.

\section{Labellum Micromorphology in Some Ophrys Taxa}

ABSTRACT: In the study, the micromorphology of labellum in samples belonging to 10 different Ophrys taxa was examined by Scanning Electron Microscopy (SEM) method and the results were presented in comparative tables. While the samples were collected from the field, they were taken to $70 \%$ alcohol, some of them were dried according to the herbarium rules and identified. The labellum samples extracted from alcohol were dissected under the stereomicroscope with scalpel and needles and placed directly into the iron apparatus of the SEM device with double-sided adhesive tapes. These samples, whose alcohol was completely evaporated by waiting for one night, were examined directly with Scanning Electron Microscope (SEM) and labellum microphotographs were taken. According to our findings, it was determined that the speculum structures are very different from each other, and the shape and distribution of the hair / papilla in the basal, median and lateral regions differ from species to species.It was also determined that the apex region differs in $O$. fusca, O. lutea, O. speculum, O. mammosa, $O$. pseudomammosa, O. heldreichii, O. umbilicata, and O. holoserica species. In summary; It was concluded that the labellum speculum and apex structure of the 1st degree and the basal, median and lateral region surface characteristics of the 2 nd degree differ widely between the species.

Keywords: Orchidaceae, Ophrys, flower, labellum, morphology, petal.

Mehmet AYBEKE (Orcid ID: 0000-0001-9512-5313), Trakya Üniversitesi, Fen Fakültesi, Biyoloji Bölümü, Balkan Yerleşkesi, Merkez, Edirne, Türkiye

*Sorumlu Yazar/Corresponding Author: Mehmet AYBEKE, e-mail: mehmetaybeke@ trakya.edu.tr 


\section{GíRiș}

Orkidelerde labellum, farklılaşmış bir petal olarak, diğer petallerden boyut, şekil, renk, doku ve / veya koku bakımından önemli ölçüde değişir. Ayrıca labellum, polinatör böcekleri çekmek için en kritik çiçek organıdır ve böcek-bitki ilişkileri üzerindeki ortak evrimsel hipotezlerin kurulmasında da en önemli noktadadır. Bilhassa Ophrys cinsinde labellumda spekulum yapısı, labellum 3 boyutlu morfolojisinin, dişi böcek koku ve duruşuna benzetildiğinden tozlaşmada erkek böcekleri çekimlemede çok önemli olduğu belirtilmiştir (Bradshaw ve ark., 2010).

Labellum şekil ve renk varyasyonları nedeniyle orkidelerde bazı taksonların teşhisi oldukça zordur veya mümkün değildir; bu nedenle halen birçok sistematik problem, çözümsüz olarak kalmaktadır (Sezik, 1984; Delforge, 2005). Özellikle farklı ortamlarda yetişen örneklerde morfolojik varyasyonlarda sapma oldukça dikkat çekici boyutlardadır (Tutin ve ark., 1968; Rossi ve ark., 1992). Bu nedenle labellum mikromorfolojisi aşağıda belirtildiği gibi, araştırıcıların odak noktası olmuştur:

Örneğin; Maxillaria cinsinin 75 taksonu incelenmiş ve papilla tipi ve tüy dağılımı gibi karakterlerle labellum mikromorfolojisinin kısmen faydalı olduğu belirtilmiştir (Davies ve Turner, 2004). Bradshaw ve ark. (2010) 32 Ophrys taksonunda labellum mikromorfolojisini incelemiştir. Spekulum, epidermal hücreler, varsa tüy tipleri incelenmiş, ayrıca TEM kesitleri ile hücrelerin ultrasütrüktürel özelliklerine bakılmıştır. İlaveten labellum mikromorfolojisi ile ilgili filogenetik analizler de yapılmıştır (Bradshaw ve ark., 2010). Bir başka çalışmada 21 değişik Platanthera, Gymnadenia, Dactylorhiza, Anacamptis, Orchis taksonlarında mahmuz morfolojisi incelenmiştir (Bell ve ark., 2009). Çünkü mahmuzda nektar üreten tipik bir abaksiyal (iç) epidermis bulunmaktadır (Stpiczynska, 2003) ve polinatör böceklerin tozlaşma esnasındaki davranışlarında da mahmuz önemli bir paya sahiptir (Bradshaw ve ark., 2008). Bir başka çalışmada Ophrys fusca ve O. lutea labellum mikromorfolojisi incelenmiş ve farklılıklar epidermal hücreleri, trikom yapısı ve papilla yapısına bağlı olarak ince ayrıntılar halinde sunulmuştur (Ascensao ve ark., 2005). Diğer başka çalışmada 4 farklı Serapias taksonunun labellum mikromorfolojisi incelenmiştir. Ayrıca bu çalışmada farklılıkların yanısıra bu labellum yapılarının (tüyler, hücreler, papilla) polinatör çekimleme ve seçiminde etkili olabileceği vurgulanmıştır (Lumaga ve ark., 2012).

Dolayısıyla labellum mikromorfolojisi orkide filogenisinde önemli olduğu gibi üreme biyolojisinde de her yönüyle çok önemli karakterlere sahiptir (Lumaga ve ark., 2012). Türkiye'deki orkidelerden 14 taksonda labellum mikromorfolojisi incelenmiştir (Süngü Şeker ve ark., 2016). Literatür araştırmalarımız sırasında bazı Orchidinae taksonlarının labellum mikromorfojisinin halen araştırılmadığı saptanmıştır. $\mathrm{Bu}$ boşluğu doldurmak üzere, bazı Ophrys taksonlarının labellum mikromorfolojisinin incelenmesi amaçlanmıştır.

\section{MATERYAL VE METOT}

Çalışmada kullanılan materyal listesi aşağıdadır (Çizelge 1). Örnekler, araziden toplandığı sırada \% 70 alkol materyaline alınmıştır. Örneklerden bir kısmı da herbaryum kurallarına göre kurutularak teşhisleri yapılmıştır (Tutin ve ark., 1968; Sezik, 1984; Delforge, 2005). Alkolden çıkarılan ve yarı nemli olan çiçeklerden labellum, bisturi ve iğnelerle Olympus SZ 71 stereomikroskop altında dissekte edilerek doğrudan üzeri çift taraflı yapışkan bantlar bulunan ve SEM cihazına ait çelik aparatlara yerleştirilmiştir. Bir gece kadar bekletilerek alkolü tamamıla uçurulan bu örnekler, doğrudan Trakya Üniversitesi Teknoloji Araştırma ve Geliştirme Uygulama ve Araştırma Merkezi (TUTAGEM) bünyesindeki Zeiss Evo LS 10 Taramalı Elektron Mikroskobu (SEM) ile incelenmiş ve labellum mikrofotoğrafları çekilmiştir. Mikrofotoğraflardan labellum yüzey morfolojik özellikleri, karşılaştırmalı tablolar halinde sunulmuştur. 
Çizelge 1. Kullanılan Ophrys taksonlarının listesi

\begin{tabular}{|c|c|c|}
\hline Takson & Herbaryum No & Lokalite \\
\hline O. speculum Link & 8174 & Çanakkale, Eceabat, Alçıtepe \\
\hline O. fusca Link & 8183 & Çanakkale, Eceabat, Alçıtepe \\
\hline O. iricolor Desf. & 8197 & Çanakkale, Eceabat, Kilitbahir \\
\hline $\begin{array}{r}\text { O. lutea Cav. var. minor (Guss.) O. et } \\
\text { E. Danesch }\end{array}$ & 8181 & Çanakkale, Gelibolu, Fındıklı \\
\hline O. sphegodes Mill. & 8250 & Edirne, Keşan, Yerlisu \\
\hline O. mammosa Desf. & 8175 & Çanakkale, Gelibolu, Fındıklı \\
\hline O. pseudomammosa Renz & 8355 & İstanbul, Germe \\
\hline O. heldreichii H.Fleischm. & 8247 & Edirne, Keşan, Beyköy, \\
\hline O. umbilicata Desf & 8203 & İstanbul, Çatalca \\
\hline O. bucephala Gölz \& H.R.Reinh. & 8209 & İstanbul, Dağyenice \\
\hline
\end{tabular}

\section{BULGULAR VE TARTIŞMA}

İncelenen Ophrys taksonlarına ait labellum mikromorfolojik özellikleri aşağıda verilmiş ve ayrıca Çizelge 2'de ayrintılı olarak sunulmuştur.

Ophrys fusca ve O. lutea spekulum papillalı olmakla beraber papilla yapısı ve tüy tapısı birbirinden farklıdır. $O$. fusca'da villos tüy daha fazla iken $O$. lutea'da yünlü, uzun iç içe, kıvırcık tüy veya oluşumları (bazal, lateral ve apeks bölgelerinde) daha fazladır. O. iricolor ise her ikisinden de farklıdır; bu taksonun spekulumunda papilla daha geniş ve velutinos tüylüdür. Ayrıca O. lutea'da apeks ve subapikal bölgede epidermal hücreler bölgesel olarak farklıdır. Buna göre; apeks bölgesi düz yüzeyli ve retikulat hücreli iken, subapikal bölgede geniş yünlü, uzun iç içe, kıvırcık yapılı papiller mevcuttur (Şekil 1-6).

O. speculum'da spekulum kısmı yoğun, buruşuk, değişken boyutta kaba küt çıkıntılarla kaplı, hücreler düzensiz olup villos tüylenme mevcuttur. Apeks bölgesi de spekulum bölgesi gibidir (Şekil 78).

O. mammosa' da spekulum konikal papilla taşırken, O. pseudomammosa'da sericeous tüylenme mevcuttur. Ayrıca O. mammosa'da bazal, medyan ve apeks bölgeleri konikal papilla taşırken sadece lateral bölgede yünlü, uzun iç içe, kıvırcık tüylenme vardır. O. pseudomammosa' da ise bazal, medyan, lateral ve apeks bölgelerinin hepsi konikal geniş papilla ile kaplıdır. "Meme" çıkıntıları her iki taksonda da (O. mammosa, O. pseudomammosa) villos tüylü iken bu tüyler, O. mammosa' da biraz daha uzundur (Şekil 9-12).

O. heldreichii: spekulum özellikleri diğer incelenen Ophrys taksonlarından çok farklıdır. Spekulum retikulat hücreli, çeperler yüzeyden yukarı doğru dik, verrucate çıkıntılı ve yüzeyde striat şeklinde çizgilidir. Bazal, medyan, lateral ve apeks bölgesinde papiller varken özellikle bu papiller, bazal bölgede, diğer bölgelerinkine göre daha dardır. Apendikste hücreler daha düzensiz olup, yüzeyinde striat çizgilenme vardır (Şekil 13).

$O$. bucephala'da deltoid papilla vardır, diğerinde (O. umbilicata) yoktur. $O$. umbilicata' da bazal ve apendiks bölgelerinde hücreler düzensiz şekilli olup verrucat çıkıntılar bazal bölgede daha dikkat çekicidir. İlaveten bu türde medyan bölgede konikal ve konikal olmayan tüy özellikli papillalar, bölgesel olarak yan yana bulunur. Apeks bölgesi çok yoğun kaba yünlü, uzun iç içe, kıvırcık tüylüdür. $O$. bucepahala ise lateral bölge, filiform papilla ve pubesent tüylüdür (Şekil 14-16).

$O$. holoserica: spekulum tüy yapıları (hafifçe şişkin sericeous tüylü), incelenen diğer tüm taksonlardan çok farklıdır. Genel olarak konikal papilla ile kaplı olmakla birlikte lateral ve apeks bölgeleri yoğun kaba yünlü, uzun iç içe, kıvırcık tüylüdür (Şekil 17-18). 
İncelenen taksonlarda genel olarak karşılaştırılmasında; spekulum yapılarının birbirinden çok farklı olduğu, bazal, medyan, lateral bölgelerde tüy / papilla şekli ve dağılımının türden türe farklılık gösterdiği tespit edilmiştir. Ayrıca apeks bölgesinin O. fusca, O. lutea, O. speculum, O. mammosa, O. pseudomammosa, O. heldreichii, O. umbilicata, O. holoserica türlerinde de farklılık gösterdiği tespit edilmiştir. Keza; papilla yapısının bile apekste en yakın türlerde (Örn. O. mammosa, $O$. pseudomammosa) farklı olduğu görülmüştür. Yine taksonlarda bazal, medyan ve lateral bölgelerde tüy veya papilla ayrıntılarının tür ayrımında önemli faydaları olmuştur. Örneğin; O. mammosa'da medyan bölge konikal papilla içerirken, $O$. pseudomammosa'da konikal geniş papillalıdır. $O$. heldreichii' de ise bazal bölge konikal papillalı iken medyan bölgede papilla yapısı "genişlemiş" özelliktedir. O. lutea'da ise "genişlemiş ve yünlü, uzun iç içe, kıvırcık yapılı papil” bulunmuştur. O. fusca' da ise yoğun villos tüylenme vardır. $O$. umbilicata' da ise, medyan bölgede "konikal papillalar (bölgesel) ve yan bölgelerinde tüy şeklinde papilla oluşumları gözlenmiştir. Son olarak; O. holoserica' da lateral bölgede konikal papilla ve kenarlarında yoğun kaba yünlü, uzun iç içe, kıvırcık tüylenme görülmüştür. $\mathrm{Bu}$ sonuçlardan, 1. derecede labellum spekulum ve apeks yapısının, 2. derecede de bazal, medyan ve lateral bölge yüzey karakterlerinin türler arasında çok farklılık gösterdiği anlaşılmaktadır.

Çizelge 2. İncelenen Ophrys taksonlarının labellum mikromorfolojik özellikleri

\begin{tabular}{ll}
\hline Takson & Spekulum ve diğer labellum bölgelerinin özellikleri \\
\hline O. fusca & Spekulum: konikal papilla ve villos tüylü. Villos tüylü (her yerde) \\
O. lutea var. minor & Spekulum: konikal papilla, \\
& Bazal: uzun yünlü, uzun iç içe, kıvırcık tüylü; lateral bölge: genişlemiş ve yünlü, uzun iç içe, \\
& kıvırcık yapılı papil şeklinde; apeks: en uç apeks bölgesi düz yüzeyli, retikulat hücreli, \\
& çeperler yüzeyden yukarı doğru dik; fakat bunun az gerisi (medyana doğru, subapikal) \\
& genişlemiş ve yünlü, uzun iç içe, kıvırcı yapılı papil şeklinde
\end{tabular}

\section{O. iricolor}

O. speculum

\section{O. mammosa}

O. presudomammosa

O. heldreichii

O. umbilicata

O. bucephala

o. holoserica
Spekulum: geniş papillalı ve uzun velutinous tüylü, bunun dışında her yer geniş papillalıdır. Spekulum: Yoğun buruşuk değişken boyutta kaba küt çıkıntılarla kaplı, hücreler düzensiz; lateral: yoğun villos tüylenme, Apeks: yoğun buruşuk değişken boyutta kaba küt çıkıntılarla kapl, hücreler düzensiz

Spekulum: konikal papilla, bazalde Meme uzantısı: uzun villos tüylü; medyan: konikal papilla, lateral: yünlü, uzun iç içe, kıvırcık tüylü tüylü; apeks: konikal papilla Spekulum: sericeous tüylü; bazal: konikal geniş papillalı, meme uzantısı: villos tüylü; medyan: konikal geniş papillalı; lateral: konikal geniş papillalı; apeks: konikal geniş papillalı

Spekulum: retikulat hücreli, çeperler yüzeyden yukarı doğru dik, verrucate çıkıntı ve yüzeyde striat şeklinde çizgili, bazal: konikal papillalı; medyan: genişlemiş papilla var; lateral: genişlemiş papilla var, boynuz: villos tüylü; apeks: genişlemiş papilla var, apendiks: hücreler striat yüzeyli ve düzensiz şekilli

Spekulum: konikal papilla ve tüy şeklinde papillalı (bölgesel olarak); bazal: striat yüzeyli, düzensiz hücreli, verrucate çıkıntılı, çeperler yüzeyden yukarı doğru dik; medyan: konikal papillalar (bölgesel) ve yan bölgelerinde tüy şeklinde papilla mevcut; apeks: çok yoğun kaba yünlü, uzun iç içe, kıvırcık tüylü tüylü, apendiks: düzensiz hücreli, düz yüzeyli

Spekulum:deltoid papillali; lateral: filiform papilla ve pubescent tüylü

Spekulum: hafifçe şişkin sericeous tüylü; bazal: konikal papillalı; lateral: konikal papillalı, en kenarı yoğun kaba yünlü, uzun iç içe, kıvırcık tüylü tüylü; apeks: konikal papillalı, apeks yanları yoğun kaba yünlü, uzun iç içe, kıvırcık tüylü tüylü

Değişik araştırmalara göre; labellar papilla yapısının konikal, obpyriform, villiform, fusiform veya clavate şekillerinde olduğu gibi büyük bir çeşitlilik gösterdiği ve bunların dağılımının önemli olduğu vurgulanmıştır (Davies ve Turner, 2004). İlaveten papilla şeklinin onun altında yatan bir fizyolojik görevle muhakkak alâkalı olduğuna dair bilgiler de mevcuttur (Davies ve Turner, 2004). Bizim bulgularmızda da papil yapısı ve dağılımı dikkatlice belirtilmiştir. 


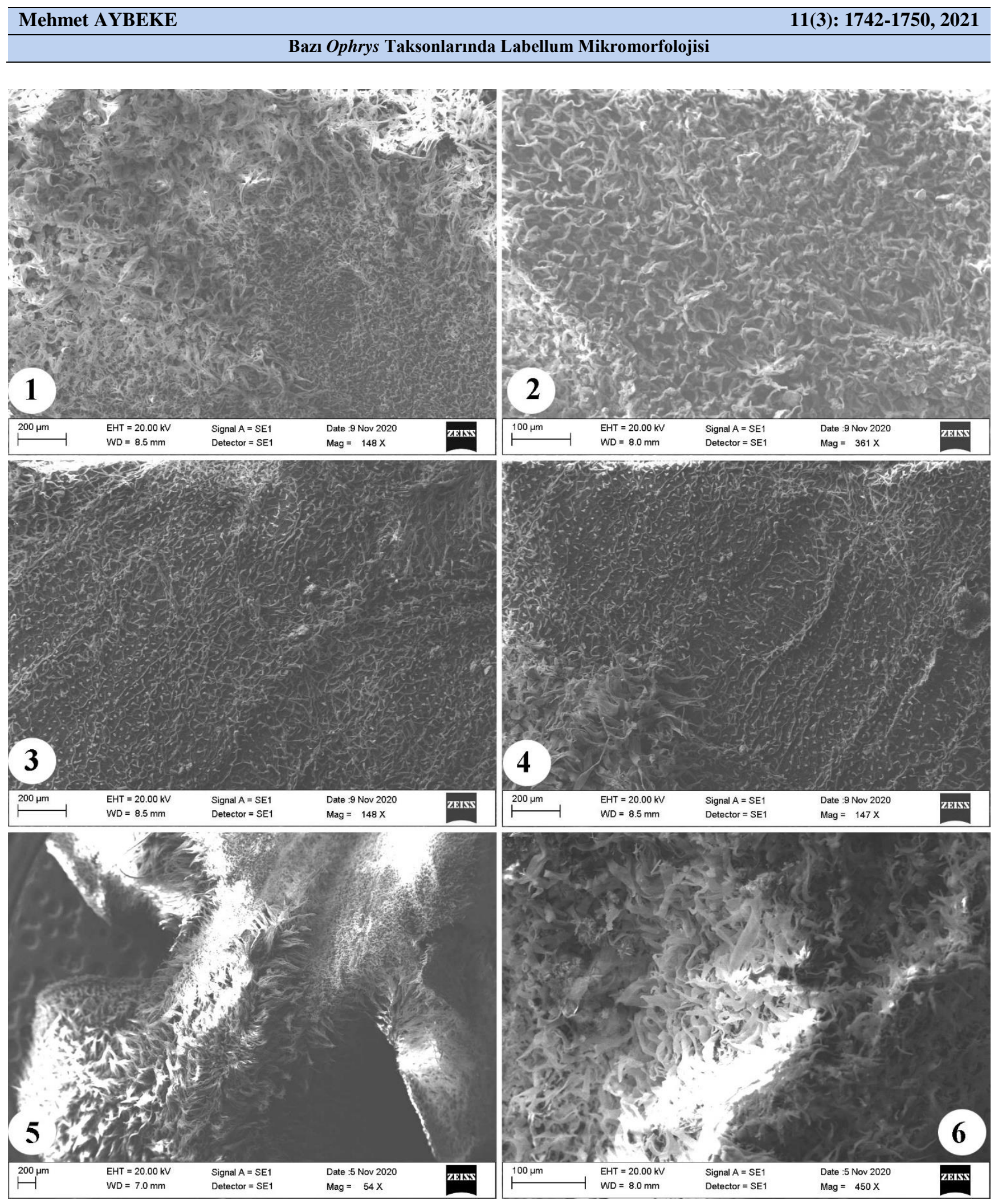

Şekil 1-6: Labellum mikromorfolojik özellikleri. O. fusca, labellum medyan bölge (1), medyan bölge spekulum (2); O.lutea var. minor, spekulum (3), spekulum apikal bölge yakınları (4); O. iricolor, spekulum genel görünüş (5), spekulum büyütülmüş (6)

Literatür taramalaramıza göre; bu türlerle ilgili benzer veya kısmen farklı sonuçlara rastlanılmıştır: Örneğin; Bradshaw ve ark. (2010)'na göre labellum yüzey yapılarının O.iricolor'da dar tüylenme ve stigmatik bölgenin pilos tüylü olduğu, O.lutea var. minor'da dar piloz tüylenme, O.speculum düz, poligonal, papillat çizgili, O.umbilicata'da ve O.heldreichii'de geniş tüylenme, O.mammosa' da dar trikom olduğu belirtilmiştir. 


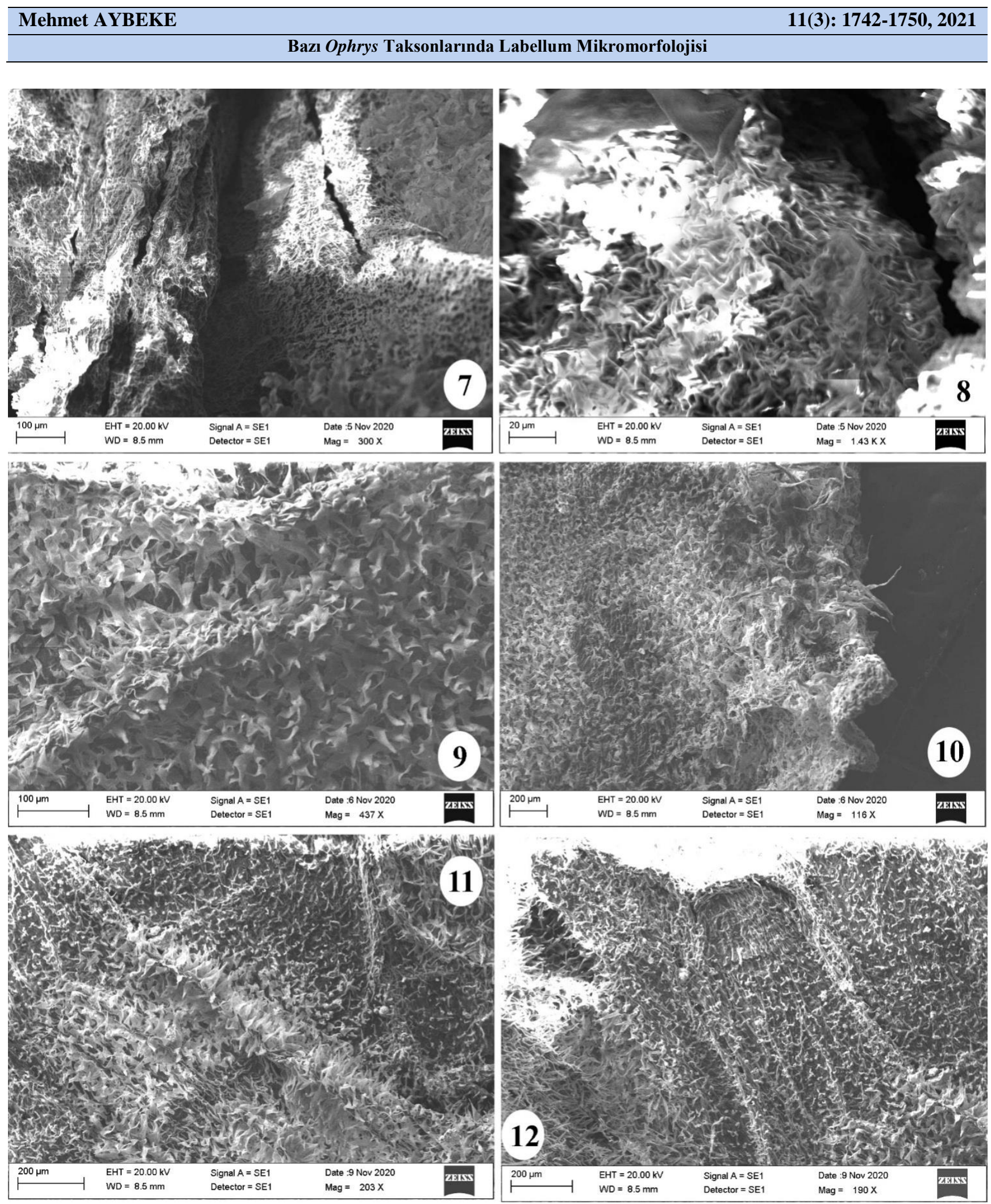

Şekil 7-12: Labellum mikromorfolojik özellikleri. O. speculum, spekulum (7-8); O. mammosa, medyan bölge (9), labellum lateral bölge (10); O. pseudomammosa, spekulum ve stigmatik boşluğa bakan kısım (bazal bölge) (11), spekulum (12) 


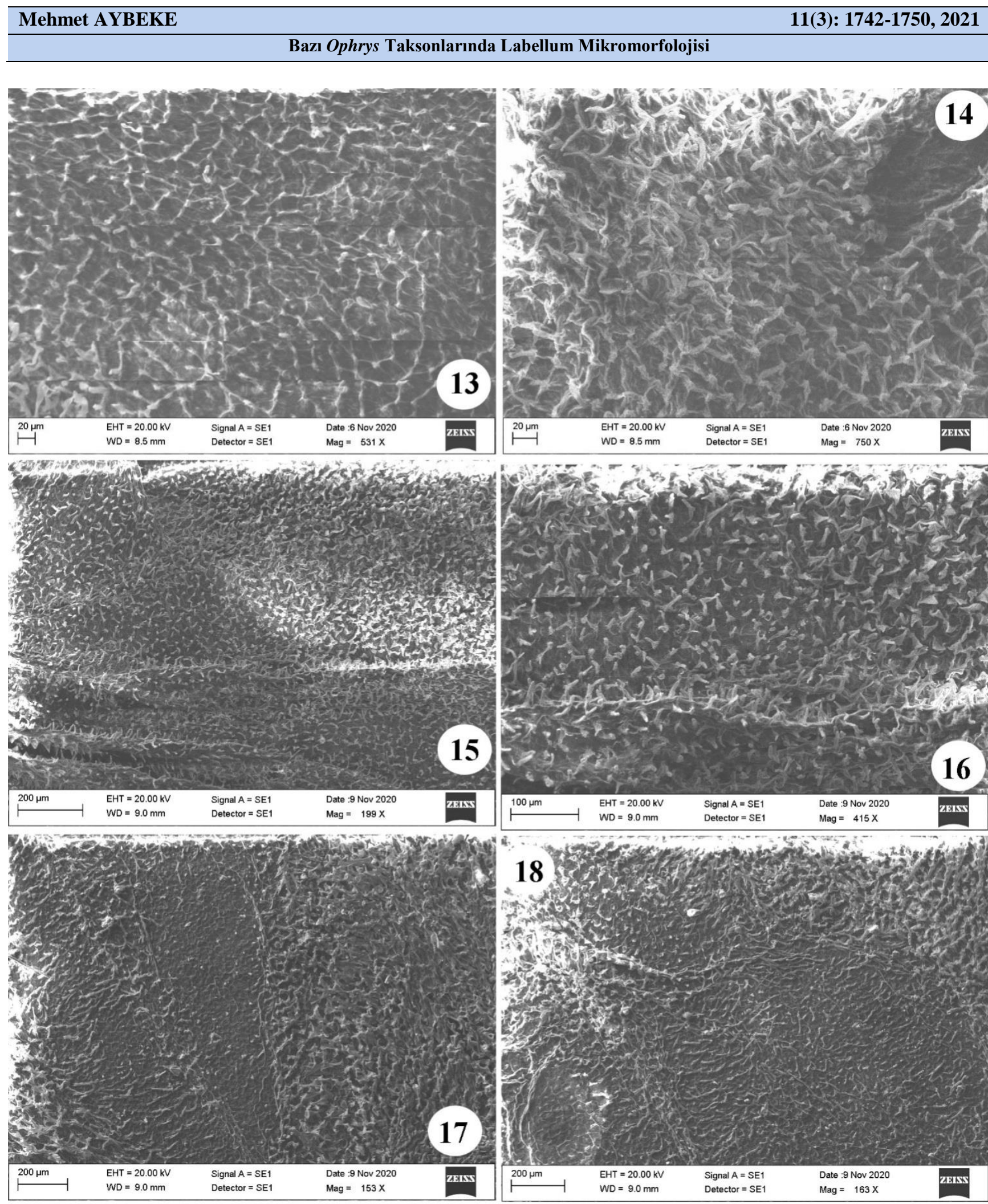

Şekil 13-18: Labellum mikromorfolojik özellikleri. O. heldreichii, spekulum (13); O. umbilicata, bazal bölge (14); O. bucephala ,spekulum bazal bölge (15-16); O. holoserica, spekulum (bazal ve yanal bölgeleri) (17), spekulum medyan bölge (18)

Ascensao ve ark. (2005)'na göre; $O$. fusca ve $O$. lutea' da aynı yapıda trikomlara rastlamışlardır. Buna göre; uzun tek hücreli trikomlar labellumun bazal bölgesinde, poligonal tabanlı kısa tek hücreli trikomlar spekulumun medyan kısmında, uzun aküminat villos trikomlar, labellumun apikal bölgesinde bulunmuştur. Ayrıca yazarlar farklılık olarak $O . f u s c a$ da villos tüylenmenin, spekulumu çevreleyen tüm kısmın ve apikal kısmın tamamını kapladığını, aksine O.lutea'da villos indumentum alanının daha küçük 
olup labellumun apikal-proksimal bölgesi ve spekuluma temaslı lateral loblarda bulunduğunu belirtmişlerdir. Bizim sonuçlarımıza göre ise villos tüylenmenin sadece $O$. fusca' da olduğu, $O$. lutea' da villos tüylenme yerine daha çok genişlemiş ve yünlü, uzun iç içe, kıvırcık yapılı papillerin olduğu tespit edilmiştir. Söz konusu farklılıkların muhtemelen değişen çevre koşullarından ve özellikle polinatör davranışlarına bağlı olarak geliştiği düşünülmektedir. Zira labellumda nektar üretiminin epidermal papilla özellikleri ve epidermal striation özellikleri ile alakalı olduğu tespit edilmiştir (Bell ve ark., 2009). Ayrica spekulumda epidermal striasyon ve pigment karakterlerinin hep birlikte spekulum parlaklığı ve çekiciliğini oldukça etkilediği belirtilmiştir (Vignolini ve ark., 2012). İlaveten labellum mikromorfolojik özellikleri üzerinden Ophrys filogenisi de incelenmiştir (Bradshaw ve ark., 2010). Dolayısıyla burada elde edilen sonuçların türlerin evrimsel üreme biyolojisine ve flogenisine katkıda bulunacağına inanılmaktadır.

\section{SONUÇ}

İncelenen Ophrys örneklerinde; spekulum yapıları, tüy / papilla şekli ve dağılımının bazal, medyan ve lateral bölgelerde türden türe farklılık göstermiştir. İlaveten; apeks bölgeleri bilhassa $O$. fusca, $O$. lutea, O. speculum, O. mammosa, O. pseudomammosa, O. heldreichii, O. umbilicata, O. holoserica türlerinde de farklıdır. Sınıflandırmada en yakın olduğu bilinen taksonların labellum ayrıntılı mikromorfolojileri, kendilerine özel papilla yapıları ve apeks bölgesindeki yüzey özellikleri bakımından farklılık göstermektedir ve bu durum tür ayrımında da önem arz edebilir. Hatta papilla yapısının bile aynı taksonda bölgesel olarak farklı olduğu görülmüştür. Örneğin; $O$. heldreichii' de bazal bölge konikal papillalı iken medyan bölgede papilla yapısı "genişlemiş" özelliktedir. O. lutea' da ise "genişlemiş ve yünlü, uzun iç içe, kıvırcık yapılı papil” bulunmuştur. Sonuç olarak; labellum ayrıntılı mikromorfolojisi her yönüyle en yakın taksonların ayırımında beklenilen faydayı sağlamıştır.

\section{TEŞEKKÜR}

Bu çalışma, Trakya Üniversitesi TÜBAP 2020 /94 kodlu proje ile desteklenmiştir.

\section{Çıkar Çatışması}

Çıkar çatışması yoktur, yazarın kendi özgün çalışmasıdır.

\section{Yazar Katkısı}

Tüm çalışma, yazarın kendisine aittir.

\section{KAYNAKLAR}

Ascensao L, A Francisco, H Cotrim and MS Pais, 2005. Comparative structure of the labellum in Ophrys fusca and O. lutea (Orchidaceae). American Journal of Botany 92(7): 1059-1067.

Bell AK, DL Roberts, JA Hawkins, PJ Rudall, MS Box and RM Bateman, 2009. Comparative micromorphology of nectariferous and nectarless labellar spurs in selected clades of subtribe Orchidinae (Orchidaceae). Botanical Journal of the Linnean Society, 160: 369-387.

Box MS, Bateman RM, Glover BJ, Rudall PJ, 2008. Floral ontogenetic evidence of repeated speciation via paedomorphosis in subtribe Orchidinae (Orchidaceae). Botanical Journal of the Linnean Society, 157: 429-454.

Bradshaw E, Paula J Rudall, DS Devey, MM Thomas, BJ Glover and RM Bateman, 2010. Comparative labellum micromorphology of the sexually deceptive temperate orchid genus Ophrys: diverse epidermal cell types and multiple origins of structural colour. Botanical Journal of the Linnean Society, 162: 504-540. 
Davies KL and MP Turner, 2004. Morphology of floral papillae in Maxillaria Ruiz. \& Pav. (Orchidaceae). Annals of Botany, 93: 75-86.

Delforge P, 2005. Guide des orchidees d'Europe, d'Afrique du Nord et du Proche Orient. Delachaux et Niestle, Paris.

Lumaga MRB, Pellegrino G, Bellusci F, Perrotta E, Perrotta I, Musacchio A, 2012. Comparative floral micromorphology in four sympatric species of Serapias (Orchidaceae). Botanical Journal of the Linnean Society, 169: 714-724.

Rossi W, Corrias B, Ardurino P, Cianchi R, Bullini L, 1992. Gene variation and gene flow in Orchis morio (Orchidaceae) from Italy. Plant Systamatic and Evolution, 179: 43-58.

Rudall PJ, Bateman RM, 2002. Roles of synorganization, zygomorphy and heterotopy in floral evolution: the gynostemium and labellum of orchids and other lilioid monocots. Biological Reviews, 77: 403-441.

Sezik E, 1984. Orkidelerimiz, Türkiye'nin Orkideleri. Sandoz Kültür Yayınları, no. 6, Istanbul.

Stpiczynska M, 2003. Nectar resorption in the spur of Platanthera chlorantha(Custer) Rchb. Orchidaceae: structural and microautoradiographic study. Plant Systematics and Evolution, 238: 119-126.

Süngü Şeker Ş, MK Akbulut, G Şenel, 2016. Labellum micromorphology of some orchid genera (Orchidaceae) distributed in the Black Sea region in Turkey. Turkish Journal of Botany, 40: 1-14.

TutinTG, Heywood VH, Burges NA, Moore DM, Valentine DH, Walters SM, Webb DA, 1968. Flora Europeae, Vol. 5, Alismataceae to Orchidaceae (Monocotyledones). Cambridge University Press, pp: 344-348, Cambridge.

Vignolini S, Davey MP, Bateman RM, Rudall PJ, Moyroud E, Tratt J, Malmgren S, Steiner U, Glover BJ, 2012. The mirror crack'd: both pigment and structure contribute to glossy blue appearance of the mirror orchid, Ophrys speculum. New Phytologist, 196: 1038-1047. 